\title{
La reforma laboral de 2010. ¿Qué reforma?
}

\author{
Francisco Javier Arrieta Idiakez \\ Profesor doctor de Derecho del Trabajo \\ Universidad de Deusto
}

Recibido: 24.11 .2010

Aceptado: 20.12 .2010

Resumen: En este estudio se analiza la reforma laboral llevada a cabo a través de la Ley 35/2010, de 17 de septiembre, de medidas urgentes para la reforma del mercado de trabajo. A tal fin, en primer lugar, se realiza una contextualización de la misma. A continuación, se abordan los tres principales objetivos pretendidos, a saber, la reducción de la dualidad existente entre contratos temporales e indefinidos, el reforzamiento de los instrumentos de flexibilidad interna y el aumento de las oportunidades de las personas desempleadas. Pero el estudio no se limita a describir los cambios realizados, sino que quiere ir más allá. Por ello, también se plantean alternativas, y, entre éstas, incluso respecto a instituciones no reformadas.

Palabras clave: reforma de 2010 sobre el mercado de trabajo, dualidad entre contratos temporales e indefinidos, flexibilidad interna, intermediación laboral.

Abstract: This study analyzes the labour market reform implemented by Law 35/2010, of 17 September, on urgent measures to reform the labour market. In order to achieve this objective, first of all, the context will be studied. Secondly, the three main objectives of the reform will be looked at, i.e, the reduction of the duality between temporary contracts and indefinite contracts, the reinforcement of instruments to obtain internal flexibility within enterprises and the increase of the possibilities of unemployed people to start working again. But this study does not only describe the changes carried out, it also seeks to give different alternatives. Moreover, within these alternatives, even institutions which have not been reformed are addressed.

Key words: 2010 labour market reform, duality between temporary contracts and indefinite contracts, internal flexibility, job placement.

Sumario: 1. Contextualización de la reforma: De aquellos polvos vienen estos lodos. 1.1. Ante viejos problemas en la senda de viejas y fracasadas soluciones 1.2. Son rumores, son rumores que se oyen, que se oyen... - 2. Los objetivos de la reforma y las medidas adoptadas al respecto. 2.1. Medidas para la reducción de la dualidad existente entre contratos temporales e indefinidos. 2.1.1. Restricción del uso injustificado de la contratación temporal. 2.1.2. Promoción de la utilización más extensa de la contratación indefinida. 2.2. Medidas para el reforzamiento de los instrumentos de flexibilidad interna. 2.2.1. Traslados colectivos y modificaciones sustanciales de las condiciones de trabajo. 2.2.2. Cláusulas de inaplicación salarial. 2.2.3. Reducción del tiempo de trabajo. 2.3. Medidas para el aumento de las oportunidades de las personas desempleadas. 
2.3.1. Bonificaciones a la contratación indefinida. 2.3.2. Contratos formativos. 2.3.3. Mecanismos de intermediación laboral.

\section{Contextualización de la reforma: De aquellos polvos vienen estos lodos}

1. Como es sabido, la actual crisis económica en España se origina como consecuencia de lo que bien podríamos llamar «efecto billar» o «efecto dominó». Pues es innegable que, en principio, las causas de la situación económica española pueden achacarse a factores externos, entre los que se encuentran «la crisis financiera internacional que dificulta el acceso a la financiación exterior y la debilidad de la economía mundial que deteriora la confianza y las expectativas del crecimiento vía sector exterior» ${ }^{1}$. Y, en consecuencia, se han desencadenado una serie de factores internos que han acabado por conducir al Estado español al mismísimo abismo, recortando la renta disponible de las familias y erosionado la competitividad de las empresas, con una sensación de caída en vacío y de que lo peor está por llegar, al no haber tocado fondo todavía. Efectivamente, los fantasmas de Grecia e Irlanda comienzan a pasearse por la agujereada Piel de Toro. Y la espada de Damocles en manos de los señores del mundo amenaza por acabar cayendo con todo su peso sobre la misma.

$\mathrm{Y}$ ante esta mezcolanza de inestabilidad, languidez y tragedia, el primero de los antídotos con cierta apariencia de seriedad ha consistido en la archiconocida reforma del mercado de trabajo. Precisamente, se dedica este estudio al análisis de las principales líneas estratégicas de la misma, comenzando con su contextualización, a la luz de algo tan objetivo y palpable como lo expresado en los Preámbulos de las dos normas que la han llevado a cabo, a saber, el Real Decreto-ley 10/2010, de 16 de julio, de medidas urgentes para la reforma del mercado de trabajo ${ }^{2}$, y la Ley 35/2010, de 17 de septiembre, de idéntica denominación ${ }^{3}$.

\subsection{Ante viejos problemas en la senda de viejas y fracasadas soluciones}

2. Una vez más la reforma laboral se ha llevado a cabo a través de un real decreto-ley, tal y como es costumbre durante las últimas dos déca-

${ }^{1}$ Analistas de Relaciones Industriales. Propuestas empresariales para salir de la crisis. En $R L, 2009$, núm. 3. Versión electrónica: www.laleylaboral.com., p. 2. Además, como se indica por los propios analistas, «esa falta de confianza en el crecimiento económico vía exterior está motivada principalmente por la difícil situación de los mercados inmobiliarios en diferentes países y el notable aumento de los precios de los alimentos y de las materias primas durante... [los últimos dos años]».

${ }^{2}$ BOE de 17 de junio de 2010, núm. 147.

${ }^{3}$ BOE de 18 de septiembre de 2010, núm. 227. 
das ${ }^{4}$. Así, la utilización abusiva del real decreto-ley para afrontar las reformas del mercado de trabajo ha vuelto a ser criticada por la doctrina, al considerarse que «un proyecto de ley tramitado por el procedimiento de urgencia hubiese permitido, desde el principio, una participación legislativa más sosegada y racional sobre las situaciones propuestas», sin precipitar la inmediata entrada en vigor de las medidas y postergar su revisión parlamentaria ${ }^{5}$.

3 . Pero, al respecto, debe reflexionarse que resulta cuanto menos curioso que el recurso al real-decreto ley se produce en situaciones de «soledad parlamentaria». Con otras palabras, siempre es fruto de una maniobra mezquina para esquivar la aludida participación sosegada y racional que debiera siempre prevalecer, dando la voz a los verdaderos representantes del pueblo, desde el primer momento.

En períodos de mayoría absoluta, se fundamenta en la arrogancia del sentirse poderoso para hacer y deshacer, pese a no contar con el apoyo del resto de grupos parlamentarios o de los agentes sociales, así como en evitar «innecesariamente» un enfrentamiento con el resto de fuerzas parlamentarias, que quizás pueda restar popularidad al partido gobernante. Por su parte, los Gobiernos en minoría, como sucede con los dos últimos, encuentran en el real-decreto ley su «fórmula mágica» para poder sobrevivir, y dar la sensación de que algo se hace. Si funciona el Diálogo Social perfecto: se traslada la sensación de consenso, de que se sabe escuchar al prójimo y se convierte el producto en altamente vendible ante la opinión pública. Luego,

${ }^{4}$ Así lo demuestran el Real Decreto-ley 18/1993, de 3 de diciembre, de medidas urgentes de fomento de la ocupación (BOE de 7 de diciembre de 1993, núm. 292); los Reales Decretos-leyes 8/1997, de medidas urgentes para la mejora del mercado de trabajo y el fomento de la contratación indefinida y 9/1997, por el que se regulan incentivos en materia de Seguridad Social y de carácter fiscal para el fomento de la contratación indefinida y la estabilidad en el empleo, ambos de 16 de mayo (BOE de 17 de mayo de 1997, núm. 118); el Real Decreto-ley 15/1998, de 27 de noviembre, de medidas urgentes para la mejora del mercado de trabajo en relación con el trabajo a tiempo parcial y el fomento de su estabilidad (BOE de 28 de noviembre de 1998, núm. 285); el Real Decreto-ley 5/2001, de 2 de marzo, de medidas urgentes de reforma del mercado de trabajo para el incremento del empleo y la mejora de su calidad (BOE de 3 de marzo de 2001, núm. 54); el Real Decreto-ley $5 / 2002$, de 24 de mayo, de medidas urgentes para la reforma del sistema de protección por desempleo y mejora de la ocupabilidad (BOE de 25 de mayo de 2002, núm. 125); el Real Decreto-ley 5/2006, de 9 de junio, para la mejora del crecimiento y del empleo (BOE de 14 de junio de 2006, núm. 141); y el Real Decreto-ley 2/2009, de 6 de marzo, de medidas urgentes para el mantenimiento y el fomento del empleo y la protección de las personas desempleadas (BOE de 7 de marzo de 2009, núm. 57).

${ }^{5}$ PAlomeque LóPez, M.C. La versión 2010 de la reforma laboral permanente. En VVAA. La reforma laboral 2010. Aspectos Prácticos (GARCía-Perrote EsCARTín, I. y MerCAder Uguina, J.R., Dirs.). Valladolid: Lex Nova, 2010, pp. 28-29. Para una crítica al uso abusivo del real decreto-ley en materia de reformas laborales puede consultarse igualmente ARRIETA IDIAKEZ, F.J. Claroscuros de la reforma de 2006 sobre el mercado de trabajo. En Estudios de Deusto, 2008, vol. 56/1, pp. 23 y 24. 
siempre será más factible conseguir algún apoyo en el parlamento, y complicar la estrategia de la oposición. ¿Y qué hacer cuando ni siquiera se cuenta con el Diálogo Social de los agentes sociales de corte centralista, tal y como ha ocurrido en la tramitación de la reforma que aquí se comenta? Entonces, basta con ganarse la confianza de los grupos parlamentarios nacionalistas. ¡Existen! Basta con acordarse de que todavía quedan más de treinta competencias por transferir. Entonces es cuando uno se percata de la gran falacia y de que la «participación legislativa sosegada y racional» en España es una quimera, lejos de verdaderos Estados como Alemania, donde, como lo atestigua la historia, son posibles grandes coaliciones entre la Unión Cristiano Demócrata (CDU) y los Social Demócratas (SPD). Y es que en España sólo parece funcionar la idea de pacto para mantener a toda costa un modelo de territorialidad aún sin definir y con cada vez más «goteras».

4. Ciertamente, el uso abusivo del real-decreto ley contradice lo preceptuado por el artículo 86.1 de la Constitución, al olvidar que conforme al mismo, solamente podrá acudirse al real decreto-ley en casos «de extraordinaria y urgente necesidad». Obviamente, ello debe justificarse, y es, precisamente, lo que se hará a continuación. No obstante, conviene recordar que el Tribunal Constitucional ya se pronunció sobre este extremo en la sentencia 68/2007, de 28 de marzo, al declarar la inconstitucionalidad y consiguiente nulidad del Real Decreto-ley 5/2002, de 24 de mayo, de medidas urgentes para la reforma del sistema de protección por desempleo y mejora de la ocupabilidad, al considerar que el Gobierno no había aportado ninguna justificación que permitiese apreciar la existencia de la situación habilitante requerida, y que, en consecuencia, los argumentos que al respecto se utilizaban en el preámbulo no sólo resultaban marcadamente teóricos y abstractos, impidiendo con ello todo control de contraste con la realidad, sino que, en buena medida, habían sido matizados — cuando no neutralizados - por la propia percepción de la realidad transmitida por el Gobierno en el debate parlamentario de convalidación, amén de que en ningún momento se justificaron cuáles serían los perjuicios u obstáculos que, para la consecución de los objetivos perseguidos, se seguirían de su tramitación por el procedimiento legislativo parlamentario, en su caso por el trámite de urgencia $\left(12 .^{\circ}\right.$ Fundamento Jurídico).

Centrándonos ya propiamente en el Real Decreto-ley 10/2010, de 16 de junio, de medidas urgentes para la reforma del mercado de trabajo, en su Preámbulo, apartado III, de entrada puede calificarse la argumentación utilizada nuevamente, y en los mismos términos del Tribunal Constitucional como «marcadamente teórica y abstracta». No puede llegarse a otra conclusión, si nos atenemos a la literalidad: «en el conjunto y en cada una de las medidas que se adoptan concurren, por la naturaleza y finalidad de las mismas, las circunstancias de extraordinaria y urgente necesidad que exige el artículo 86 de la Constitución Española como presupuesto habilitante para la aprobación de un real decreto-ley». 
Ni siquiera en las circunstancias mencionadas acto seguido se aprecian los requisitos constitucionales exigidos.

En primer lugar, no hay más ciego que el que no quiere ver, y resulta chocante que, con la que está cayendo, y seguirá cayendo tras la grave situación económica de Irlanda y con el estancamiento del desempleo en España, se señale que «los indicadores de coyuntura que se van conociendo apuntan de forma cada vez más nítida a una incipiente salida de la situación recesiva, y, en consecuencia, al inicio de una fase económica cualitativamente diferente de la atravesada en los últimos dos años». Realmente, nada o poco puede esperarse tras las ilusas visiones de los famosos «brotes verdes» que nunca aparecieron, y observando que permanecemos inmersos en un prolongadísimo otoño que parece que nunca va a acabar, en el que brillan por su ausencia los bosques de árboles perennes y abundan, por el contrario, los tristes bosques de árboles de hoja caduca, enfermos, por cierto, por los hongos que aumentan en sus troncos cada día.

Pero es que la ceguera se acompaña, además, de osadía. ¡Incluso hay algo de futurología! Me refiero al hecho de que se esté pensando en una «nueva etapa que... requiere de medidas diferentes de las adoptadas hasta este momento, que pongan el acento en sentar las bases de un nuevo modelo de crecimiento más equilibrado y generador de empleo de calidad, algo... que sólo resulta posible implementando con urgencia reformas de calado en el ámbito de las relaciones laborales» ${ }^{6}$. Y surgió la «Bella Panacea»: ¡Las reformas laborales!

En efecto, parece ser que esta reforma constituye una especie de «piedra filosofal» capaz de cambiar artificialmente el caótico modelo productivo español. Es suficiente con remitirse al Preámbulo de la Ley 35/2010, de 17 de septiembre, de medidas urgentes para la reforma del mercado de trabajo.

De este modo, en su apartado I, se hace primero hincapié en que la reforma laboral se sitúa en una «perspectiva integral», al haberla ya anunciado en la Estrategia de Economía Sostenible presentada el 2 de diciembre de 2009 por el Presidente de Gobierno en el Congreso de los Diputados ${ }^{7}$. En concreto, se afirma que dicha estrategia busca «acelerar la renovación de nuestro modelo productivo...», así como «fortalecer los pilares de nuestro estado de bienestar y... a generar más empleo». Acto seguido, es en el apartado II donde se concreta la misma idea, reforzando el papel de la reforma laboral, al indicar que la misma «tiene como objetivo esencial contribuir a la reducción del desempleo e incrementar la productividad de la economía española». Tal

\footnotetext{
${ }^{6}$ La cursiva es mía, con la intención de recalcar las principales afirmaciones que también serán objeto de comentario a lo largo de este estudio.

${ }^{7}$ Y una vez más se repite la palabra mágica: «sostenible». Resulta que ahora todo es «sostenible», curiosamente cuando todo es antagónicamente hablando «insostenible». A estas alturas, uno siente que dicho vocablo ha sido totalmente pervertido y que, por ende, ha perdido todo valor, hasta haberse convertido en vacío, hueco.
} 
y como ha advertido la doctrina, en ello reside la novedad ${ }^{8}$. Independientemente de las medidas de índole laboral que se han adoptado, y que serán comentadas en los apartados siguientes, llama la atención este hecho.

En verdad, las deficiencias en la regulación del mercado de trabajo deben corregirse para ajustar el Derecho a la realidad, más si cabe si la misma es tan volátil y debe convivir en una economía globalizada. Ahora bien, es ridículo pensar que las reformas laborales tienen tanto peso como para renovar el modelo productivo e incrementar la productividad. Obviamente, debe existir una sinergia entre ambas realidades, pero el mercado de trabajo previamente tiene que contar con un marco adecuado. Dicho con otras palabras, primero son las estructuras productivas, lo sustantivo, y después las estructuras laborales, lo adjetivo o procedimental. Por mucho que se «toque y retoque» la normativa laboral nada se conseguirá si no se aborda la cuestión de raíz. Se han perdido tres largas décadas, y ahora no pueden afrontarse de golpe y porrazo todas y cada una de las carencias del sistema. Sencillamente, es imposible. Sin embargo, ello no obsta para comenzar a caminar por la senda adecuada. El problema es que se camina sin rumbo fijo, y siempre por los mismos senderos angostos y tortuosos, por el permanente otoño de bosques tristes. Como botón de muestra, sirvan las siguientes apreciaciones, teniendo en cuenta que cada uno de los movimientos que deben producirse se asemejan a los movimientos de figuras sobre un tablero de ajedrez, son decisivos:

(a) La dependencia energética encarece la producción, eleva los impuestos y todo ello acaba repercutiendo en trabajadores, consumidores y usuarios. Puesto que en las actuales sociedades es evidente que nadie desea retroceder en el tiempo a la época de las cavernas, o, simplemente, a la época del candil, el debate de las fuerzas energéticas debe plantearse sin ambages y sin miedos. Deben renovarse las obsoletas y peligrosas instalaciones y crearse nuevos organismos, seguros y eficaces. Además, la libertad de empresa en estos sectores no debe estar reñida con la necesaria intervención pública. Debe existir competencia sana en el mercado, sin pretensiones políticas ni monopolios encubiertos de naturaleza privada que tratan por todos los medios (OPAs hostiles, modificaciones legislativas, operaciones indirectas con empresas extranjeras...) de concentrar el poder, de centralizar este sistema. Lo dicho, frente a estas perniciosas tendencias, la centralidad debe fundarse en una intervención pública que posibilitando la competencia de distintos entes con autonomía a lo

\footnotetext{
${ }^{8}$ CaVAs Martínez, F. y Luján Alcaraz, J. Introducción. En VVAA. Guía práctica de la reforma laboral de 2010 (CAvas Martínez, F. y Luján Alcaraz, J., Coords.). Murcia: Laborum, 2010, pp. 13-14.
} 
largo y ancho de toda la geografía, sepa velar, ante todo, por los principios de justicia, igualdad y solidaridad, sin olvidar la proyección a todos los ámbitos de la naturaleza de un Estado que se define sobre el papel como «social»y «democrático de Derecho».

(b) Las infraestructuras para el transporte de mercancías son deficitarias, obsoletas y sin conexiones adecuadas. Comenzando por el ámbito marítimo, debe tomarse en serio la especial situación geoestratégica de la península, para apostar definitivamente por el transporte marítimo. ¿Por cuánto tiempo más deben permanecer en el último de los cajones de sus señorías los proyectos de leyes sobre la Marina Mercante? ¿No es suficiente con observar la cantidad de puestos de trabajo destruidos en este sector por mera dejadez, o la falta de mandos españoles en nuestra flota cada vez más mermada? ¿Cómo se pueden liberalizar importantes cuestiones en materias de Puertos del Estado y de la Marina Mercante, sin contar previamente con normas que aporten rigor y coherencia sobre todos los ámbitos afectados? Unas modernas infraestructuras portuarias y una regulación global de todos los sectores afectados deben otorgar a la península la importancia que merece por su situación geoestratégica en el tráfico marítimo. España debe convertirse, así, en el principal interesado en la instauración de las denominadas autopistas de mar, y para ello debe defender en todos los foros esta cuestión, apostando por un servicio de calidad y respetuoso con las condiciones de trabajo justas y el medio ambiente, conforme a la amplia normativa internacional existente al respecto. La calidad del servicio tiene un precio, pero a largo plazo es lo que debe prevalecer frente al dumping social de antaño. La aplicación de la I+D+i y la denuncia de las situaciones flagrantes de vulneración de la normativa internacional tienen aquí un basto terreno en el que actuar. Por su parte, en el ámbito del transporte terrestre, es fundamental comunicar los puertos con líneas ferroviarias de alta velocidad, de forma y manera que se aporte rapidez y seguridad en el tráfico y que se descongestionen las carreteras y se ahorre el coste en constantes adaptaciones y nuevas construcciones en autopistas y autovías. En suma, las líneas ferroviarias de alta velocidad son importantes, pero no deberían centrarse única y exclusivamente en la libre circulación de personas, al tiempo que tampoco debería olvidarse la intracomunicación entre lo que podríamos denominar territorios periféricos. Para ello, también deben plantearse nuevas soluciones ferroviarias en un segundo nivel, con posibilidades de conectarlas, igualmente, en los puntos estratégicos, a las vías de alta velocidad.

c) La situación del primer sector es deplorable, patética. Al alto precio que debieron pagar en 1986 la pesca, la agricultura y la minería con la incorporación de España a la Comunidad Económica 
Europea, le han seguido largos años de travesía por el desierto de la inacción. Con la salvedad de la minería, donde los problemas son más que acusados, y habría que pensar más en la recolocación de los trabajadores afectados, que en subvencionarla a saco roto, a cambio de un puñado de votos o del silencio del sector, la agricultura y la pesca sí que pueden ser sectores emergentes, si se apuesta por la activación de políticas adecuadas. Las empresas de economía social deben jugar un papel importante en estos sectores, para lo que debe invertirse en formación en los principios inherentes a esta forma de producción que cuenta ni más ni menos con soporte constitucional en el artículo 129.2. Asimismo, se debe apostar por contar con todo el proceso productivo, a saber, se requiere el aumento de empresas manipuladoras, altamente especializadas en sistemas de congelación, conservación y calidad alimenticia. Todo debe aprovecharse, tal y como se hace en Japón con los recursos haliéuticos. Finalmente, tampoco cabe desconocer la importancia que en el sector pesquero deben adquirir las instalaciones dedicadas a la acuicultura, lo que requiere una seria apuesta por preservar la calidad de nuestras aguas. He ahí otro basto campo de actuación para la I+D+i.

d) Por último, deben retomarse ciertos aspectos subrayados en el Preámbulo de la Ley 35/2010, al afectar éstos, igualmente, a la productividad. En este sentido, en el apartado I, se alude al crecimiento económico y del empleo anterior a la crisis. Pero ¿de qué crecimiento y empleo hablamos? ¿Solamente de números pasajeros? Parece ser que sí, que poco importan los términos cualitativos y los cálculos a largo plazo, basados en un modelo social. Sin embargo, el legislador tropieza con sus propias palabras, al reconocer que la principal causa de la pérdida de empleo obedece a «la caída de la actividad productiva, derivada, en un primer momento, del colapso de los cauces habituales de crédito y endeudamiento que sustentaron de forma decisiva el consumo y la inversión en la pasada etapa expansiva. Luego, se está reconociendo que no todo eran bondades en aquel crecimiento y aquel empleo. Y prosigue el legislador, indicando que en España las consecuencias de la crisis han sido peores debido a las «diferencias en la estructura productiva del crecimiento económico, como a algunas particularidades estructurales de nuestro mercado laboral, que las reformas abordadas en las últimas décadas no han logrado eliminar o reducir de forma sustancial». De todo ello cabe extraer varias conclusiones:

-En primer lugar, durante años ha existido un consumismo exarcerbado, se ha vivido por encima de las posibilidades reales. ¿Y quién es responsable de tal actitud? Quien ha vendido la imagen de que todo va bien. Todavía recuerdo con indignación el eslogan de un anuncio publicitario de una conocida multinacional 
que también cuenta entre nosotros con centros comerciales: «La avaricia me vicia». No es que vivamos en una sociedad sin valores, sino que los valores son los que son, son los que se fomentan.

-En segundo lugar, y en íntima conexión con la conclusión anterior, durante años ha existido en España una desmesurada expansión del sector de la construcción y de la burbuja inmobiliaria ${ }^{9}$. Con otras palabras, la construcción, junto al turismo, son los sectores que posibilitaron el crecimiento en términos numéricos, pero también los que han supuesto la existencia de importantes diferencias en la estructura productiva. En relación con la anterior conclusión, es evidente que el endeudamiento de muchas familias, el hecho de que se encuentren hoy hipotecadas hasta las cejas, se debe a los precios desproporcionados de las viviendas. El consumismo promovido y los cauces de crédito inadecuados, incluso para financiar vacaciones o unos cuantos días en la nieve, han hecho imposible el ahorro para fomentar el gasto o la inversión en otra serie de productos de primera necesidad y, principalmente, de previsión. Poco o nada se ha hecho en este último campo. Aun conociendo las carencias a futuro de nuestro Sistema de Seguridad Social, se ha seguido considerando que el nivel complementario es «cosa de ricos», tal y como se ha podido incluso escuchar públicamente a alguno de los ministros actuales. Nuevamente, que lejos estamos de otros Estados como Alemania ${ }^{10}$. $Y_{Y}$ que rápido se ha traicionado nuestra propia historia, al esfuerzo de instituciones tan veneradas en el pasado como el Instituto de Reformas Sociales, el Instituto Nacional de Previsión (INP) o el espíritu de nuestras primeras cajas de ahorros! Entre nosotros, en Euskadi, que lejos ha quedado la imagen de aquellos propagandistas como el gipuzkoarra Gregorio Mugika, a la sazón responsable del INP en Gipuzkoa, que durante las dos primeras décadas del siglo XX no dudó, con la colaboración de la Caja de Ahorros de Guipúzcoa, en publicar escritos o en recorrer pueblos y caseríos para instruir a sus paisanos en la importancia de la previsión, en especial respecto a los riesgos de vejez y supervivencia, y lo hizo sin complejos ni miramientos en sus dos lenguas: euskera y castellano ${ }^{11}$.

\footnotetext{
${ }^{9}$ Véase García Serrano, C., Malo M.A. y Pérez Infante, J. Para una reforma laboral negociada. En $R L, 2010$, núm. 9. Versión electrónica: www.laleylaboral.com., p. 1.

${ }^{10}$ Para un acercamiento a las reformas en Alemania, véase IBARRECHE LARRAZ, M. La reforma del Sistema de pensiones en Alemania. En REDT, 2010, núm. 145.

${ }^{11}$ Véase ARRIETA IDIAKEZ, F.J. Euskarazko testu juridikoen idazkuntza itzulpenaren bidez: lan-zuzenbidea adibide gisa. En VVAA. Nomografía y corredacción legislativa. Bilbao: Universidad de Deusto, 2009, pp. 188 y 189.
} 
-En tercer lugar, no puede olvidarse que el crecimiento económico a través de la construcción y del sector turístico se ha producido, en gran medida, a costa del dumping social y de la economía sumergida, aprovechándose de la mano de obra barata de inmigrantes, y produciéndose la explotación laboral más dura y la vulneración de derechos humanos más flagrante respecto a los irregulares. Ello debe servir para no mirar al otro lado, o para no seguir subvencionando a Estados como Marruecos con la finalidad de que hagan el trabajo sucio, impidiendo a cualquier precio la movilidad de personas migrantes. Los inmigrantes, llegaron, llegan y seguirán llegando, y en la medida en que no se regule adecuadamente su integración, con idénticos derechos y deberes que el resto, continuarán los problemas.

-En cuarto y último lugar, cabe preguntarse una vez más por la «extraordinaria y urgente necesidad» para afrontar la reforma laboral vía real decreto-ley, cuando expresamente se constata que siguen existiendo los mismos defectos estructurales en nuestro mercado de trabajo que antes de la crisis. Sinceramente, el carácter permanente de los defectos estructurales del sistema desde mediados de los ochenta del siglo pasado hace de sí imposible que se hable de «urgente necesidad».

Avanzando en los argumentos utilizados en el Real Decreto-ley 10/2010 para justificar la utilización de un real decreto-ley para implementar la reforma, en segundo lugar se hace hincapié en que «todas aquellas medidas que se refieren a grupos específicos de trabajadores o que contienen incentivos para la contratación o para el mantenimiento de los puestos de trabajo han de tener efectividad inmediata, pues la tramitación parlamentaria de una norma con rango de ley provocaría graves distorsiones del mercado de trabajo durante el tiempo en que se produjera esa tramitación».

En la misma línea, en tercer lugar, se señala que la situación de empleo «tampoco permite aplazar la adopción de aquellas medidas que persiguen animar a los empresarios a contratar nuevos trabajadores, dinamizar el mercado de trabajo fomentando una intermediación laboral más intensa y fortalecer o incentivar mecanismos de flexibilidad interna alternativos a la destrucción de puestos de trabajo».

Pues bien, en torno a estas dos últimas justificaciones basta con tener en cuenta dos aspectos mencionados en los preámbulos del Real Decreto-ley 10/2010 y de la Ley 35/2010, para concluir su improcedencia. Por un lado, si se reconoce que los problemas estructurales del mercado de trabajo provienen de tiempo atrás, debido al fracaso de reformas anteriores, es obvio que tiempo ha habido para debatir y discernir con sosiego las medidas concretas a adoptar. Por otro lado, se indica que es desde 2008 cuando se ha disparado el desempleo en España; por consiguiente, ¿qué se nos quiere 
trasladar, que dos años no son suficientes para estudiar las medidas oportunas?

El verdadero problema con el que se ha encontrado el Gobierno se revela algo después, al establecerse que «en el convencimiento de que el consenso de los interlocutores sociales constituye la vía más eficaz para introducir cambios sustanciales en el sistema de relaciones laborales, el Gobierno ha prorrogado el debate hasta apurar las posibilidades de alcanzar un acuerdo. Sin embargo, agotados los esfuerzos por alcanzarlo, la adopción de las medidas que se consideran necesarias para dinamizar el mercado de trabajo y mantener el empleo existente no pueden dilatarse por más tiempo».

Es decir, el problema es que al Gobierno, como se suele decir, «le ha pillado el toro», y se ha quedado sin el Diálogo Social, esa fórmula que le permitió en la legislatura anterior y que le ha permitido en parte de la actual que sean otros quienes le hagan el trabajo, y le «saquen las castañas del fuego». ¿Y qué cabe decir del banco social de dicho diálogo? La respuesta a esta cuestión debe extraerse del análisis de las concretas medidas adoptadas, pero pueden adelantarse varias ideas en forma de preguntas. ¿Por qué aquellos que aceptaron la reforma laboral de 2006 se niegan ahora a aceptarla? ¿Por qué aquellos que callan ante la legislación simbólica, retórica o semántica ahora gritan ${ }^{12}$ ¿Son realmente de tanto calado las modificaciones introduci-

${ }^{12}$ Desdentado Bonete nos ilustra sobre este fenómeno. Por ello, merece traer a colación aquí sus palabras: «El largo plazo ha desaparecido del horizonte político y el imperio postmoderno de lo efímero... se adueña también de una legislación prêt à porter $\mathrm{y}$, por tanto, rápidamente desechable. El problema se agrava, porque esas intervenciones coyunturales parten normalmente de una visión parcial y urgente de la superficie de los problemas y, de esta forma, se altera la unidad del ordenamiento. No se trata sólo de un desorden producido por el crecimiento cuantitativo de las normas y la mala técnica legislativa. Se ha dicho también que estamos ante un Derecho que se ha vuelto dúctil o, más exactamente, manipulable y en el que el ideal de justicia se separa de la ley, que se convierte en un mero instrumento de intervención coyuntural o de simple gestión. Esto es ya más grave que el simple deterioro técnico de la ley. Pero recientemente estamos asistiendo a otro fenómeno: el de la legislación simbólica, retórica o semántica. Se trata — dice Nieto— de la práctica cada vez más extendida de aprobar determinadas leyes para dar la sensación de que se está haciendo algo importante en relación con determinadas cuestiones de actualidad cuando en realidad no se hace nada o se hace muy poco. La legislación aparece así como una forma degradada de propaganda, mediante leyes vacías de contenido propiamente normativo, pero superpobladas de declaraciones de principios, de programas de acción, de buenos propósitos, de aspavientos de corrección político-lingüística o de novedosas proclamaciones de derechos que ya se encuentran reconocidos en la Constitución o en otras normas» (DESDENTAdo BonETE, A. Sobre la legislación simbólica en el Estatuto del Trabajo Autónomo. El traje nuevo del emperador. En RDS, 2009, núm. 44. Versión electrónica: www.tirantonline.com., TOL1.465.260, p. 2). El autor cita como ejemplos de esta tendencia la parte laboral de la Ley Orgánica 3/2007, de 22 de marzo, para la igualdad efectiva de mujeres y hombres (BOE de 23 de marzo de 2007, núm. 71), la Ley 27/2005, de 30 de noviembre, de fomento de la educación y la cultura de la paz (BOE de 1 de diciembre de 2005, núm. 287) y, sobre todo, la Ley 20/2007, de 11 de julio, del Estatuto del trabajo autónomo (BOE de 12 de julio de 2007, núm. 166). 
das en la actual reforma como para rechazarla? ¿No será que la situación se ha convertido en insostenible, superados los cuatro millones de desempleados y con la imagen de España por los suelos a nivel internacional, y que mediáticamente resulta mucho más cómodo echarse a las calles? Y aun hay más. ¿Qué se ha conseguido en la práctica con las huelgas de 29 de junio (sindicatos nacionalistas en Euskadi) y de 29 de septiembre (sindicatos centralistas en todo el Estado)? ¿Es coherente manifestarse contra la reforma laboral siendo afiliado de una de las centrales convocantes y al de poco aceptar el cargo de Ministro de Trabajo? Más allá de las oportunas respuestas, huelga decir que es momento para la reflexión, para analizar los «puntos críticos y las alternativas a las elecciones sindicales y a la mayor representatividad» ${ }^{13}$, teniendo en cuenta la verdadera representación de estos agentes, el número de afiliados y sus principales fuentes de financiación. Es momento para regular conforme a los nuevos tiempos el derecho fundamental de huelga, regulado, curiosamente, por una norma preconstitucional, el Real Decreto-ley 17/1977, de 4 de marzo, sobre relaciones de trabajo ${ }^{14}$, sin perder de vista que el fin último de este derecho fundamental es solucionar los conflictos colectivos, como medio de presión, y no aumentar los previamente existentes. En último término, debe replantearse la madurez del modelo de representación de los trabajadores, pues como se ha afirmado «las circunstancias han cambiado radicalmente: la política de pancartas y manifestaciones ya no es la más adecuada. Antes al contrario, los sindicatos y las organizaciones empresariales, en un ejercicio de responsabilidad desarrollado bajo los auspicios y supervisión del poder político, tienen que ser capaces de convenir nuevas propuestas de políticas sociales o de reformular las ya existentes, dentro siempre de un proceso reglado donde todos los implicados participen con lealtad y buena disposición» ${ }^{15}$.

Tampoco es aceptable que se trate de justificar el uso del real decreto-ley alegando que ello responde «al método que ha sido habitual en las reformas laborales llevadas a cabo... en las últimas décadas». Ciertamente, ello no quiere decir que se haya actuado correctamente, y menos cuando existe una sentencia del Tribunal Constitucional que pone las cosas en su sitio.

Finalmente, resulta del todo desproporcionado acudir a un real decretoley para transponer al ordenamiento jurídico español la Directiva

\footnotetext{
${ }^{13} \mathrm{Al}$ respecto, y bajo el mismo título, consúltese la obra de Álvarez CuESTA, H. Granada: Editorial Comares, 2006, 221. pp.

${ }^{14}$ BOE de 9 de marzo de 1977, núm. 58.

${ }^{15}$ Hyman, R. Trade unions and the politics of the European social model. En Economic and Industrial Democracy, 2005, vol. 26, núm. 1, pp. 28 y 32. Citado en Fernández FerNÁNDEZ, R. y MEgino FERNÁNDEZ, D. El largo y tortuoso camino de la reforma del mercado laboral español: La «flexibilidad/seguridad» como antídoto frente a la crisis. En Estudios Financieros. Revista de Trabajo y Seguridad Social: Comentarios, casos prácticos: recursos humanos, 2010, núms. 329-330, p. 37.
} 
2008/104/CE, de 19 de noviembre de 2008, relativa al trabajo a través de empresas de trabajo temporal ${ }^{16}$, cuando la misma otorga para ello a los Estados miembros un plazo de dos años que espira el 5 de diciembre de 2011, sin que valga como pretexto que se desea «conceder a la negociación colectiva un plazo suficiente para llevar a cabo... [dicha tarea]». ¿Es que tampoco para esto dos años no son suficientes?

5. Una vez analizadas las razones alegadas para justificar la utilización del real-decreto-ley, de cara a materializar la reforma laboral, sólo resta valorar hasta que punto puede compartirse la afirmación del legislador de que las medidas adoptadas obedecen a «reformas de calado en el ámbito de las relaciones laborales». No obstante, antes conviene comentar algunas propuestas que se realizaron con anterioridad a la reforma y que sirvieron para adelantar las principales directrices de la misma.

\subsection{Son rumores, son rumores que se oyen, que se oyen...}

6. Con anterioridad a la reforma, y ante la inactividad del Gobierno, la doctrina había comenzado a proponer toda una batería de medidas con las que afrontar la crisis.

7. Dentro del variopinto conjunto de medidas, De La ViLLa GiL no titubeó en afirmar que todos deberíamos apretarnos el cinturón, enumerando una serie de garantías y sacrificios para los trabajadores, empresarios, sindicatos e incluso consumidores ${ }^{17}$.

Así, respecto a los trabajadores, parte del principio básico del Derecho laboral tuitivo y protector de conservación del negocio jurídico, al señalar que «a los trabajadores hay que garantizarles, hasta donde sea posible, el puesto de trabajo, para que no pierdan su poder adquisitivo». Por tanto, solamente, y subsidiariamente, ante pérdida de renta, opta por las prestaciones de desempleo, «por los efectos gravísimos que representa para el interesado y para su círculo familiar y, más allá de eso, para la dosis indispensable de normalidad productiva» la falta de renta de trabajo o renta social. La contrapartida de todo ello se fundamenta para este autor en el «sacrificio de la congelación salarial».

En idénticos términos, para con los empresarios establece que «hay que imponerles el sacrificio de mantener los puestos de trabajo», frenando «la complaciente permisividad de las regulaciones de empleo saldadas con pérdidas de puestos de trabajo a cambio de indemnizaciones satisfactorias, sobre todo desde la óptica de los representantes unitarios o sindicales». La

${ }^{16}$ DOUE de 5 de diciembre de 2008, L 327.

${ }^{17}$ DE La VILLa GiL, L.E. ¿Entra dentro del Derecho del Trabajo la tarea de resolver situaciones de crisis extremas? En VVAA. Medidas laborales para empresas en crisis (SEMPERE Navarro, A.V., Dir.). Cizur Menor (Navarra): Aranzadi, 2009, pp. 36-41. 
contrapartida vendría de la mano del permiso para establecer dobles escalas salariales vía negociación colectiva, «a cambio de contrataciones nuevas y no para sustituir a trabajadores cesados, siempre que los menores niveles salariales de entrada se apliquen a todos los trabajadores ingresados en la empresa a partir de determinada fecha conforme a un plan asimismo colectivamente negociado» ${ }^{18}$.

En torno a los sindicatos aboga por «garantizarles la intervención efectiva en las negociaciones previas a la adopción de medidas excepcionales, aunque sin facultades de veto», así como su participación en las comisiones de seguimiento de tales medidas. Pero les exige mayor implicación con el interés general, y, en particular, respecto al incremento de la productividad, a través de acuerdos estratégicos, lo que supone el abandono de técnicas de bloqueo y de mera obtención de un expediente de regulación de empleo. Incluso propone replantear la situación de aquellos sindicatos que pese a bajísimas tasas de afiliación reciben importantes subvenciones públicas, al tiempo que realza a los pocos sindicatos que pagan su actuación con el esfuerzo económico de sus afiliados.

Por último, la medida más curiosa que plantea este autor se centra en los consumidores, entendiendo que «son los trabajadores los consumidores por antonomasia». En efecto, propugna la estabilidad de los precios de los servicios públicos indispensables para la subsistencia, así como de veinte productos básicos de alimentación, de forma y manera que la subida de los mismos se financie con recursos públicos ad hoc. Como contrapartida, los consumidores deberían «aceptar el sacrificio de la restricción del crédito máximo que puedan contraer para la compra de objetos que no sean de primera necesidad o indispensables para la realización de su actividad profesional».

En suma, llama la atención, sobre todo, la defensa del principio conservación del negocio jurídico o de la empresa, tan castigado últimamente, no ya solamente en situaciones económicas críticas, sino que también en situaciones en las que simplemente se deja de ganar.

Además, dicho principio se encuentra fuertemente vinculado al principio de estabilidad en el empleo, auténtico valor a tutelar en nuestras sociedades, al tratarse el empleo de un bien relativamente escaso. Sin embargo, tiende a afirmarse que una tendencia extrema en este sentido genera mercados de trabajo rígidos, perjudiciales para la empresa y, por tanto, también para los trabajadores, llegando a ser incluso incompatible con un razonable ámbito de decisión empresarial, expresamente reconocido en el artículo 38 de la Constitución, bajo el principio de libertad de empresa. Por ello, siguiendo la estrategia de Lisboa, se vende la moto de que la solución pasa por conciliar la fle-

${ }^{18}$ Efectivamente, debe tenerse en cuenta al respecto lo dispuesto por el Tribunal Constitucional en su sentencia 27/2004, de 4 de marzo. 
xibilidad y la seguridad en las relaciones de trabajo, es decir, por aceptar la llamada «flexiguridad» o «flexiseguridad», que supone: (a) La flexibilidad del mercado de trabajo, facilitando el despido; (b) un alto grado de políticas pasivas de empleo, y, especialmente, de prestaciones por desempleo; y (c) un sistema fuerte de políticas activas de empleo, destinadas, básicamente, a la empleabilidad de los trabajadores ${ }^{19}$.

$\mathrm{Y}$ en este sentido, algunos sectores repiten machaconamente que el mercado de trabajo español resulta excesivamente rígido, y tratan de implementar medidas que tienden a su flexibilización.

8. Es así como se planteó por parte de la CEOE la posibilidad de establecer un «contrato indefinido no fijo», caracterizado por ser una nueva modalidad contractual abierta a los desempleados y a los trabajadores con contrato temporal, en la que, durante los dos primeros años, el empresario podría extinguirlos libremente, sin más requisito que avisar con 7 días de antelación y pagar una indemnización de 8 días de salario. Transcurridos esos dos años, el empresario podría optar por la extinción del contrato o por convertirlo en indefinido fijo, que podría darse, igualmente, por finalizado sin más obligación para el empresario que preavisar al trabajador con un mes de antelación y abonarle una indemnización de 20 días de salario por año, con un tope de 12 mensualidades. Todas las extinciones serían consideradas acordes a Derecho, salvo en los períodos de licencias de maternidad o paternidad, en los que se declararían nulas salvo incumplimiento del trabajador, el cual, en los demás casos, sólo podría reclamar las tasadas indemnizaciones y los salarios correspondientes a los períodos de preaviso no respeta$\operatorname{dos}^{20}$.

En parecidos términos, la Fundación de Estudios de Economía Aplicada (FEDEA) propuso la creación del «contrato único indefinido» que supondría la eliminación de todos los contratos temporales, excepto del contrato de interinidad, para la sustitución de trabajadores en baja temporal, y la regulación de una indemnización por extinción proporcional a la antigüedad en el centro de trabajo, con una escala que oscilaría entre los 8 días para el primer año, 12 para el segundo, 15 para el tercero, 20 para el cuarto, 25 para el quinto y 36 en adelante. Además, dicha extinción no requeriría causa alguna, ni calificación, excepto en los despidos disciplinarios y los despidos discriminatorios, puesto que los primeros, obviamente, no darían lugar a indemniza-

${ }^{19}$ Respecto a estas cuestiones, véase Montoya Melgar, A. Estabilidad en el empleo, globalización económica y «flexiguridad». En VVAA. El despido disciplinario. Homenaje al Profesor Juan Antonio Sagardoy Bengoechea (GIL y GIL, J.L. y Del VAlLe, J.M., Coord.s). Madrid: Ediciones Cinca, 2009, pp. 98-109.

${ }^{20}$ Rodríguez-Piñero y Bravo-Ferrer, M. Sobre el contrato de trabajo «único». En $R L$, 2009, núm. 10. Versión electrónica: www.laleylaboral.com., p. 2. 
ción alguna, y, los segundos, serían calificados como nulos a todos los efec$\operatorname{tos}^{21}$.

9. Por el contrario, ninguna de ambas propuestas ha prosperado en la reforma laboral. Quizás debido a que rápidamente se abrió la caja de los truenos, y las mismas se vieron constreñidas a topo tipo de críticas, al señalarse que las mismas vulneraban el Convenio 158 OIT, de 1982, sobre la terminación de la relación de trabajo por iniciativa del empresario, el artículo 24 de la Carta Social Europea, el artículo 30 de la Carta Europea de Derechos Fundamentales, la Directiva 98/59/CE, de 20 de julio de 1998 y la interpretación que del artículo 35 de la Constitución Española ha hecho el Tribunal Constitucional, entre otras, en su sentencia 192/2003, de 27 de octubre de 200322.

10. Aun así, no faltó quien, a pesar de aceptar tales críticas, supo elogiar los méritos del contrato de trabajo único. En esa línea, LAHERA ForTEZA se centró en la idea que late tras la propuesta de contrato único, a saber, el errático modelo dual vigente de contratos temporales y despidos individuales improcedente ${ }^{23}$. Asimismo, con astucia, supo trasladar las críticas vertidas sobre el contrato único a lo dispuesto en el vigente artículo 56.2 del Real Decreto Legislativo 1/1995, de 24 de marzo, por el que se aprueba el Texto Refundido de la Ley del Estatuto de los Trabajadores (TRLET) ${ }^{24}$. Y sobre esa base se esforzó en reestructurar la propuesta inicial, revelando sus aspectos positivos, sus riesgos, puntos débiles y posibles mejoras, así como sus alternativas ${ }^{25}$.

Independientemente de la no aceptación por el Gobierno de tales propuestas, la verdad es que las medidas adoptadas en la reforma siguen la tendencia flexibilizadora subyacente en las mismas, tal y como se verá a continuación.

11. Por el contrario, también se ha apreciado en la doctrina cierta reticencia ante tales postulados. Tal vez inspirada en la «rigiseguridad» laboral alemana de la que nos instruyó magníficamente ARUFE VARELA ${ }^{26}$, ciertos autores han criticado que se califique al mercado de trabajo español como rígido o que se intenten aportar mayores dosis de flexibilidad al mismo. Res-

\footnotetext{
${ }^{21} \mathrm{Al}$ análisis de esta propuesta se refieren, entre otros: GoerLiCh PeSET, J.M. ¿Contrato único o reforma del despido por causas empresariales? En $R L, 2010$, núm. 1. Versión electrónica: www.laleylaboral.com., p. 3. RoDRÍGUEZ-PIÑERO ROYO, M.C. Algunos aspectos jurídicos de la propuesta de contrato único. En $R L, 2010$, núm. 1. Versión electrónica: www.laleylaboral.com., pp. 3 y 5.

${ }^{22}$ Véanse al respecto RodríGueZ-PiÑERo y Bravo-Ferrer, M., ob. cit., pp. 2-4. GoerLiCh PeSET, J.M., ob. cit., p. 4 y ss. Rodríguez-Piñero Royo, M.C., ob. cit., p. 8 y ss.

${ }^{23}$ LAHERA ForteZA, J. Elogio y crítica a la propuesta del contrato de trabajo único. En $R L, 2010$, núm. 1. Versión electrónica: www.laleylaboral.com., pp. 1-3.

${ }^{24}$ BOE de 29 de marzo de 1995, núm. 75.

${ }^{25}$ LAHERA ForTEZA, J., ob. cit., pp. 4-16.

${ }^{26}$ Arufe VArela, A. Flexiseguridad laboral danesa y rigiseguridad laboral alemana. En $A S, 2008$, núms. 7 y 8.
} 
pecto a la primera crítica, se ha justificado adecuadamente que lejos de la rigidez pretendida, el ordenamiento laboral español es uno de los más flexibles de Europa ${ }^{27}$. Por su parte, en torno a la segunda crítica se ha considerado que la «flexiseguridad», en los términos mencionados anteriormente, resultaría inadecuada para el modelo español, pues «el abandono de una política legislativa basada en medidas de prevención primaria [v.gr. estabilidad en el empleo], provocaría tal incremento en los costes secundarios [v.gr. desempleo] que ni la Seguridad Social ni el Estado de Bienestar español estarían, hoy por hoy, capacitados para soportar. Lo que irremediablemente se traduciría en la traslación de dichos costes a los propios trabajadores afectados o a sus familias. Lo que lejos de presentarse como una mejora, supondría un retroceso social difícilmente tolerable» ${ }^{28}$.

\section{Los objetivos de la reforma y las medidas adoptadas al respecto}

12. Los objetivos de la reforma obedecen, según el apartado I del preámbulo de la Ley 35/2010 a las siguientes debilidades estructurales del mercado laboral español:

(a) Peso significativo de los trabajadores con contrato temporal, en comparación con el resto de Estados miembros de la Unión Europea, lo que ha traído consigo una fuerte segmentación o dualidad entre trabajadores indefinidos y temporales.

(b) Escaso desarrollo de las posibilidades de flexibilidad interna en las empresas conforme a la legislación actual.

(c) Insuficiente capacidad de colocación de los servicios públicos de empleo.

La mera observancia de estos objetivos demuestra que la reforma se vuelve a encontrar con los males endémicos existentes en España desde mediados de los ochenta, es decir, desde que se fomentó la cultura de la temporalidad. En conclusión, todas las reformas anteriores han sido baldías. Y respecto a las concretas medidas adoptadas en la nueva reforma, se ha dejado constancia en el apartado anterior de que la senda escogida no augura

${ }^{27}$ Fernández Fernández, R. y Megino Fernández, D., ob. cit., pp. 18-24. Estos autores analizan las áreas específicas del ordenamiento donde la flexibilidad se muestra con mayor claridad y vigor, a saber, la entrada en el mercado de trabajo de recursos humanos; la variabilidad de las condiciones laborales; la ordenación del tiempo de trabajo; la construcción de la estructura remunerativa; la extinción del nexo contractual.

${ }^{28}$ Beltrán DE Heredia Ruiz, I. Estabilidad en el empleo, «flexiseguridad» y crisis: una aproximación desde la perspectiva de la eficiencia de las normas laborales. En $R L, 2010$, núm. 17. Versión electrónica: www.laleylaboral.com., pp. 19-20. 
nada positivo ${ }^{29}$. Profundicemos, por ende, en el contenido de las concretas medidas adoptadas para enfrentarse a tales debilidades.

\subsection{Medidas para la reducción de la dualidad existente entre contratos tem- porales e indefinidos}

13. Las medidas adoptadas con tal finalidad, asimismo, pueden agruparse en dos grandes campos de actuación.

\subsubsection{RESTRICCIÓN DEL USO INJUSTIFICADO DE LA CONTRATACIÓN TEMPORAL}

14. La restricción del uso injustificado de la contratación temporal se pretende conseguir a través de las siguientes medidas:

(a) El establecimiento de un límite temporal máximo en los contratos para obra o servicio determinado: De este modo, con la reforma desaparece el carácter incierto de la duración de esta modalidad contractual temporal, que con anterioridad dependía del carácter de la obra o servicio a realizar; así, a partir del 18 de junio de 2010 , estos contratos no podrán tener una duración superior a tres años ampliables hasta doce meses más por convenio colectivo de ámbito sectorial estatal o, en su defecto, por convenio colectivo sectorial de ámbito inferior. Además, como sucede con el resto de contratos temporales, una vez transcurridos estos plazos, los trabajadores adquirirán la condición de trabajadores fijos de la empresa [artículo 15.1.a) del TRLET].

Es más, en ese sentido, el empresario deberá facilitar por escrito al trabajador, en los diez días siguientes al cumplimiento de los plazos indicados, un documento justificativo sobre su nueva condición de trabajador fijo de empresa, so pena de cometer una infracción leve. Y a efectos probatorios, el trabajador podrá solicitar, por escrito, al Servicio Público de Empleo correspondiente un certifica-

\footnotetext{
${ }^{29}$ La poca o ninguna fe en la misma ha quedado patente, igualmente, en gran parte de la doctrina. Por todos, y con rúbricas más que significativas de sus trabajos, MoLINA NAVARRETE, C. Reforma 2010 del mercado de trabajo: una nueva «milonga» del «capitalismo de casino». En Estudios Financieros. Revista de Trabajo y Seguridad Social: Comentarios, casos prácticos: recursos humanos, 2010, núm. 328, pp. 8-61; ABRIL LARRAÍNZAR, M.P. y MEGINO FERNÁNDEZ, D. «El laberinto del fauno» de la reforma laboral. Pocas luces y muchas sombras. En Estudios Financieros. Revista de Trabajo y Seguridad Social: Comentarios, casos prácticos: recursos humanos, 2010, núm. 328, pp. 66-138. Molina NAVARRETE, C. Un nuevo acto del «gran teatro» de la reforma laboral 2010: una reforma «para reformar» o de la «galería de los disparates». En Estudios Financieros. Revista de Trabajo y Seguridad Social: Comentarios, casos prácticos: recursos humanos, 2010, núm. 331, pp. 64-125.
} 
do de los contratos de duración determinada o temporales celebrados; en tal supuesto, el Servicio Publico de Empleo emitirá dicho documento y lo pondrá en conocimiento de la empresa en la que el trabajador preste sus servicios [artículo 15.9 del TRLET y artículo 6 del Texto Refundido de Ley de Infracciones y Sanciones en el Orden Social, aprobado por el Real Decreto Legislativo 5/2000, de 4 de agosto (TRLISOS) ${ }^{30}$.

Debe objetarse a esta medida, a pesar de ser realmente novedosa, el hecho de no abordar los verdaderos problemas existentes en torno a esta modalidad contractual. Dicho con otras palabras, debería haberse hecho hincapié en el objeto de este contrato, a saber, las obras y servicios temporales con autonomía y sustantividad propia. Mientras que no se aborde la extrema flexibilización con la que se ha venido interpretando dicho objeto por parte de la negociación colectiva y de la jurisprudencia, de nada servirá el límite temporal establecido ${ }^{31}$.

(b) La introducción de algunos ajustes en la regla instaurada en la reforma de 2006 para evitar el encadenamiento o concatenación de contratos temporales: Estos ajustes responden a las críticas que en su momento se realizaron por parte de la doctrina, y que con el tiempo se ha podido observar que las mismas no fueron gratuitas, debido al escaso éxito de la regulación anterior ${ }^{32}$.

En consecuencia, teniendo en cuenta tales críticas, la reforma ha matizado que se entenderán sujetos al límite establecido en el artículo 15.5 del TRLET también los supuestos de sucesión o subrogación empresarial conforme a lo dispuesto legal o convencionalmente.

Igualmente, a través de la modificación de la Disposición Adicional decimoquinta del TRLET se ha dispuesto que los límites existentes en torno a la duración máxima del contrato para obra o servicio determinado y de la concatenación de contratos temporales surtirán efectos también en el ámbito de las Administraciones públicas y sus organismos públicos vinculados o dependientes. Tales efectos se traducirán en que el trabajador afectado continuará desempeñando el puesto que venía ocupando hasta que se proceda a su cobertura por los procedimientos ajustados a Derecho, momento en el que

${ }^{30}$ BOE de 8 de agosto de 2000, núm. 189.

${ }^{31}$ En este sentido véase SiRvent HeRnándeZ, N. La delimitación del objeto del contrato para obra o servicio determinado en la negociación colectiva y la jurisprudencia. En RGDTSS, 2010, núm. 22, pp. 3 y 8-19. Más extensamente, véase GuALDA AlCALÁ, F.J. La causa del contrato de obra o servicio determinado: caracterización legal y práctica judicial. Albacete: Bomarzo, 2010, pp. 47-89 y 91-103.

${ }^{32}$ Cfr. Arrieta Idiakez, F.J. La reforma de 2006 sobre el mercado de trabajo. Principales repercusiones en la contratación temporal. En $A L, 2007$, núm. 15, pp. 1797-1806. 
se producirá la extinción de la relación laboral, salvo que el mencionado trabajador acceda a empleo público, superando el correspondiente proceso selectivo.

Ahora bien, estos límites de cara a la Administración pública, tienen sus excepciones. Por una parte, la duración máxima del contrato por obra o servicio determinado no será de aplicación a los contratos celebrados por las Administraciones públicas y sus organismos públicos vinculados o dependientes, ni a las modalidades particulares de contrato de trabajo contempladas en la Ley Orgánica $6 / 2001$, de 21 de diciembre, de Universidades ${ }^{33}$, o en cualesquiera otras normas con rango de ley cuando estén vinculados a un proyecto específico de investigación o de inversión de duración superior a tres años (apartado 2 de la Disposición Adicional decimoquinta). Por otra parte, para que las reglas del encadenamiento sean aplicables sólo se tendrán en cuenta los contratos celebrados en el ámbito de cada una de las Administraciones públicas, sin que formen parte de ellas, a estos efectos, los organismos públicos, agencias y demás entidades de Derecho público con personalidad jurídica propia vinculadas o dependientes de las mismas. Y tales reglas no serán de aplicación respecto de las modalidades particulares de contrato de trabajo contempladas en la Ley Orgánica 6/2001 anteriormente mencionada o en cualesquiera otras normas con rango de ley.

Como puede apreciarse, estas limitaciones perturban la estabilidad, especialmente, en un ámbito de actuación decisivo a futuro como es el campo de la investigación. La reforma mantiene la precariedad existente hasta la fecha en dicho campo, lo que impide obtener un desarrollo adecuado en políticas de $\mathrm{I}+\mathrm{D}+\mathrm{i}$ a través de una verdadera carrera profesional ${ }^{34}$.

Centrándonos en otra de las novedades introducidas, es positivo que junto a la «misma empresa» también se tenga en cuenta al «grupo de empresa», como ámbito dentro del cual se puede desarrollar un puesto de trabajo, a los efectos de la regla establecida para evitar el encadenamiento. Y lo mismo puede decirse respecto a la matización realizada en torno a que el puesto de trabajo puede ser el ocupado con anterioridad u otro diferente. El problema radica en que el legislador se resiste a definir el «grupo de empresa» desde el punto de vista laboral, por lo que habrá que acudir, como hasta ahora, a los criterios jurisprudenciales existentes sobre la materia.

${ }^{33}$ BOE de 24 de diciembre de 2001, núm. 307.

${ }^{34}$ Respecto a la estabilidad necesaria en dicho campo véase Moreno GENÉ, J. El personal investigador en formación. Régimen jurídico-laboral y de Seguridad Social. Valencia: Tirant lo Blanch, 2008, pp. 14 y 15. 
Por último, siguen sin solucionarse dos aspectos que merecen ser criticados. En primer lugar, respecto a la concatenación llevada a cabo no respecto a una misma persona, sino que a través de la rotación de distintos trabajadores en un mismo puesto de trabajo, se mantiene la incoherencia de regular que «la negociación colectiva establecerá requisitos dirigidos a prevenir la utilización de contratos de duración determinada...» en esos casos, y de no introducir dicho aspecto en el contenido mínimo del convenio colectivo exigido por el artículo 85.3 del TRLET. Por consiguiente, en los supuestos de concatenación por rotación se sigue dejando la pelota en el tejado de los agentes sociales. En segundo lugar, se mantiene el dicho popular de que «hecha la ley hecha la trampa», pues, al igual que con anterioridad a la reforma, quedan fuera del régimen del encadenamiento, ni más ni menos que los contratos formativos, de relevo e interinad. Es más, el campo de las salvedades se amplía tras la reforma a los contratos temporales celebrados en el marco de programas públicos de empleo-formación, así como a los contratos temporales que sean utilizados por empresas de inserción debidamente registradas y el objeto de dichos contratos sea considerado como parte esencial de un itinerario de inserción personalizado.

(c) El aumento de la indemnización por finalización de contratos temporales: Se ha modificado el artículo 49.1 del TRLET, en la medida en que se ha aumentado la cantidad indemnizatoria de 8 días a 12 días de salario, por cada año de servicio, sin perjuicio de la mejora establecida vía convenio colectivo, pacto o contrato, a pagar por expiración del tiempo convenido, o realización de la obra o servicio determinado, si ésta finaliza antes de haberse agotado la duración inicialmente prevista. Por lo demás, se siguen excluyendo, salvo mejora vía convenio/pacto/contrato, y aplicación, por tanto, del principio de norma más beneficiosa o, en su caso, de la consolidación de la mejor condición establecida en contrato de trabajo, los supuestos de contrato de interinidad y de los contratos formativos.

Pero, sin duda, lo más curioso respecto al incremento de esta indemnización es su aplicación gradual y postergada. En el apartado II del Preámbulo de la Ley 35/2010, se establece en ese sentido que «razones de prudencia aconsejan implantar este incremento de manera gradual y progresiva por la incidencia que su aplicación inmediata pudiera suponer sobre la creación de empleo». Entonces, la pregunta es obligada: ¿Cómo casan dicha prudencia y regulación gradual con la «extraordinaria y urgente necesidad» habilitante del real decreto-ley?

Independientemente de que con el incremento a 12 días de la indemnización se iguala la cuantía a pagar en estos casos con la indemnización a pagar por finalización del contrato entre las empre- 
sas de trabajo temporal y sus trabajadores, contratados para ser cedidos a las empresas usuarias, no se entiende muy bien que reporta esta medida a la reducción de la dualidad del mercado de trabajo.

La forma en la que se aplicará la graduación se ha recogido en la nueva Disposición Transitoria decimotercera del TRLET, de acuerdo con el siguiente calendario: Ocho días de salario por cada año de servicio para los contratos temporales que se celebren hasta el 31 de diciembre de 2011; nueve días de salario por cada año de servicio para los contratos temporales que se celebren a partir del 1 de enero de 2012; diez días de salario por cada año de servicio para los contratos temporales que se celebren a partir del 1 de enero de 2013; once días de salario por cada año de servicio para los contratos temporales que se celebren a partir del 1 de enero de 2014; doce días de salario por cada año de servicio para los contratos temporales que se celebren a partir del 1 de enero de 2015.

\subsubsection{PROMOCIÓN DE LA UTILIZACiÓN MÁS EXTENSA DE LA CONTRATACiÓN INDEFINIDA}

15. De cara a conseguir esta promoción se han articulado las siguientes medidas:

(a) Nueva regulación del contrato de fomento de la contratación indefinida: Aunque el legislador sostenga en el apartado II del Preámbulo de la Ley 35/2010 que «queda incólume» la modalidad de contrato indefinido de carácter ordinario, ello es una verdad a medias. Es verdad que se centra una vez más, desde la reforma de 1997, en la regulación del contrato de fomento de la contratación indefinida, bajo el pretexto de que «no ha venido cumpliendo en los últimos años la finalidad que reza en su enunciado, a saber, promover el acceso a contratos de carácter indefinido de los colectivos que más dificultades encuentran en la actualidad para obtenerlos». Lo que sucede es que se ha ampliado de tal manera el ámbito subjetivo para poder celebrar esta modalidad contractual, que se ha pervertido su función originaria de dirigirse a grupos concretos de trabajadores que presentan problemas para insertarse en el mercado laboral ${ }^{35}$. Concretamente, entre los trabajadores incluidos a su ámbito de aplicación se encuentran (Disposición Adicional primera de la Ley 12/2001, de 9 de julio,

${ }^{35}$ En este sentido, LujÁn AlCARAZ, J. El contrato para fomento de la contratación indefinida tras el Real Decreto-ley 10/2010, de 16 de junio, de medidas urgentes para la reforma laboral. En $A S, 2010$, núm. 7 (Tribuna). Versión electrónica: www.westlaw.es. (BIB 2010\1422), p. 5. 
de medidas urgentes de reforma del mercado de trabajo para el incremento del empleo y la mejora de su calidad ${ }^{36}$ ):

Las mujeres en los dos años inmediatamente posteriores a la fecha del parto o de la adopción o acogimiento de menores; las mujeres desempleadas que se reincorporen al mercado de trabajo tras un período de inactividad laboral de cinco años; mujeres desempleadas víctimas de violencia de género y de trata de seres humanos; parados que lleven, al menos, un mes inscritos ininterrumpidamente como demandantes de empleo, desempleados que, durante los dos años anteriores a la celebración del contrato, hubieran estado contratados exclusivamente mediante contratos de carácter temporal, incluidos los contratos formativos; desempleados a quienes, durante los dos años anteriores a la celebración del contrato, se les hubiera extinguido un contrato de carácter indefinido en una empresa diferente; trabajadores que estuvieran empleados en la misma empresa mediante un contrato de duración determinada o temporal, incluidos los contratos formativos, celebrados con anterioridad al 18 de junio de 2010, a quienes se les transforme dicho contrato de fomento de la contratación indefinida con anterioridad al 31 de diciembre de 2010; trabajadores que estuvieran empleados en la misma empresa mediante un contrato de duración determinada o temporal, incluidos los contratos formativos, celebrados a partir del 18 de junio de 2010 (estos contratos podrán ser transformados en un contrato de fomento de la contratación indefinida con anterioridad al 31 de diciembre de 2011 siempre que la duración de los mismos no haya excedido de seis meses, salvo en los contratos formativos, en los que no se tendrá en cuenta tal limitación).

Claro está, la universalización subjetiva producida con esta medida permite que aunque se alardee de haber respetado las cuantías establecidas para los diversos supuestos de extinción, en realidad se ha convertido en regla general lo que venía siendo la regla excepcional, es decir, el abaratamiento del despido objetivo improcedente, de 45 días de salario por año trabajado con un tope de 42 mensualidades, a 33 días de salario por año trabajado con un tope de 24 mensualidades. Asimismo, no debe olvidarse que correspondiendo la opción entre readmisión o indemnización al empresario, el contrato para el fomento de la contratación indefinida se entenderá extinguido en la fecha del despido cuando el empresario reconozca

${ }^{36}$ BOE de 10 de julio de 2001, núm. 164. 
la improcedencia del mismo y ofrezca al trabajador la indemnización legal, depositando en el Juzgado de lo Social a disposición del trabajador la diferencia entre la indemnización ya percibida por el trabajador según el artículo 53.1.b) del TRLET y la de 33 días por año de servicio correspondiente al despido objetivo improcedente en esta clase de contratos. Y ello es de suma importancia, puesto que cuando el trabajador acepte la indemnización o cuando no la acepte y el despido sea declarado improcedente, la cantidad correspondiente a salarios de tramitación quedará limitada a los devengados desde la fecha del despido hasta la del depósito, salvo cuando el depósito se realice en las cuarenta y ocho horas siguientes al despido, en cuyo caso no se devengará cantidad alguna.

En ese sentido, con la nueva reforma se posibilita que la improcedencia del despido objetivo no solamente se deba a la declaración judicial, sino que también cabe el reconocimiento como tal por el empresario, abriéndose también aquí, y ahora sin lugar a dudas, la posibilidad del despido exprés del artículo 56.2 del TRLET.

Además de todas esas facilidades para obtener el despido más barato, se atribuye al trabajador la carga probatoria, cuando alegue que la utilización del procedimiento de despido objetivo no se ajusta a derecho porque la causa real del despido es disciplinaria.

Por otro lado, resulta contradictoria e inútil la prohibición de concertar contratos para el fomento de la contratación indefinida por las empresas que en los seis meses anteriores a la celebración del contrato hubieran realizado extinciones de contratos indefinidos ordinarios por causas objetivas declaradas o reconocidas como improcedentes o hubieran procedido a un despido colectivo, si, posteriormente, se les permite, en ambos supuestos, la recolocación, vía contrato para el fomento de la contratación indefinida, en distintos puestos de trabajo o en distintos centros de trabajo de la empresa o grupo de empresa. Evidentemente, con tal medida se crea empleo, pero a través de una maniobra innoble.

(b) Reducción de las cantidades a abonar por las empresas en concepto de despido colectivo y despido por causas objetivas, cuando se trate de contratos indefinidos: Como advierte el legislador, en el apartado II del Preámbulo de la Ley 35/2010, esta medida no ha supuesto variación en las cuantías establecidas para estos supuestos extintivos. La reducción se pretende conseguir por medio de una doble operación, en los contratos de carácter indefinido, sean ordinarios o de fomento de la contratación indefinida (Disposición Transitoria tercera de la Ley 35/2010):

- Conforme a la primera operación, a partir del 18 de julio de 2010, cuando el contrato se extinga por despido colectivo, por despido basado en causas objetivas o por lo preceptuado en el 
artículo 64 de la Ley 22/2003, de 9 de julio, Concursal ${ }^{37}$, una parte de la indemnización que corresponda al trabajador será objeto de resarcimiento al empresario por el FOGASA, en una cantidad equivalente a ocho días de salario por año de servicio, prorrateándose por meses los períodos de tiempo inferiores al año, y en las condiciones establecidas a tal efecto.

- La segunda operación se posterga, hasta la entrada en funcionamiento del Fondo de capitalización mencionado en la Disposición Adicional décima de la Ley 35/2010. Así, según lo preceptuado por dicha disposición, «el Gobierno, en el plazo máximo de un año a partir del 18 de junio de 2010, previa consulta con las organizaciones empresariales y sindicales más representativas, aprobará un proyecto de ley por el que, sin incremento de las cotizaciones empresariales, se regule la constitución de un Fondo de capitalización para los trabajadores, mantenido a lo largo de su vida laboral, por una cantidad equivalente a un número de días de salario por año de servicio a determinar. Dicha regulación reconocerá el derecho del trabajador a hacer efectivo el abono de las cantidades acumuladas a su favor en el Fondo de capitalización en los supuestos de despido, de movilidad geográfica, para el desarrollo de actividades de formación o en el momento de su jubilación. Las indemnizaciones a abonar por el empresario en caso de despido se reducirán en un número de días por año de servicio equivalente al que se determine para la constitución del Fondo. El Fondo deberá estar operativo a partir de 1 de enero de 2012».

En el primer caso, se corre el riesgo de cargar en demasía al FOGASA, y de llevar a la práctica el viejo dicho de que «quita y no pon se acaba el montón», dejando al descubierto las funciones típicas de dicha institución. El segundo caso no merece comentario alguno, hasta que se materialice efectivamente el Fondo de capitalización. Nuevamente, nos encontramos ante la legislación simbólica y retórica de la que nos habló DeSDENTADo Bonete. Lo que sí parece evidente es que el legislador ha querido inspirarse en el modelo Austríaco o sistema Abfertigung neu, aunque de manera meramente refleja ${ }^{38}$.

${ }^{37}$ BOE de 10 de julio de 2003, núm. 164.

${ }^{38} \mathrm{Al}$ respecto véase Velasco PorTERo, M.T. y FröHLICH, M. Los sistemas alemán y austríaco como modelos de referencia de la reforma laboral en España. En $A L, 2010$, núm. 14. En versión electrónica: www.laleylaboral.com., pp. 9-11. 
(c) La nueva redacción de las causas del despido por razones empresariales: Como afirma GonZÁLEZ GonZÁLEZ, «el problema viene determinado porque en el año 2009 el $80 \%$ de los despidos que se tramitaron en los órganos jurisdiccionales del orden social fueron declarados improcedentes... porque la empresa en el momento del juicio ya estaba desaparecida y no acudía al acto, o bien porque no practicaba la prueba necesaria que acreditase la causa invocada para la extinción ${ }^{39}$. Pero tampoco debe olvidarse el problema mencionado por DesDentado Bonete, al referirse al «auge del despido "exprés" y... [al] declive del despido económico» ${ }^{40}$, que trae causa, sobre todo, de los problemas procedimentales y de la incertidumbre respecto a la calificación final en los despidos fundados en razones empresariales ${ }^{41}$.

Por todo ello, se ha procedido a unificar las distintas causas económicas, técnicas, organizativas o de producción de los despidos colectivos y objetivos. De forma y manera que, en la actualidad, el artículo 52 del TRLET, relativo al despido por causas objetivas, se remite a las causas previstas en el artículo 51 del TRLET sobre despido colectivo.

Precisamente, la gran novedad de la reforma en este campo reside en el intento realizado por concretar tales causas, con la finalidad de proporcionar «una mayor certeza tanto a trabajadores y a empresarios como a los órganos jurisdiccionales en su tarea de control judicial». El problema es que en ese intento, se han ampliado las causas para instar el despido, y ello volverá a crear dudas interpretativas y soluciones dispares. Tal vez, el mejor ejemplo de todo ello lo constituye la definición dada a las «causas económicas», al establecerse que concurrirán las mismas «cuando de los resultados de la empresa se desprenda una situación económica negativa, en casos tales como la existencia de pérdidas actuales o previstas, o la disminución persistente de su nivel de ingresos, que puedan afectar a su

\footnotetext{
${ }^{39}$ GonZÁlez GonZÁlez, A. Las indemnizaciones por despido en la última reforma del mercado de Trabajo. En $I L, 2010$, núm. 13, p. 4.

${ }^{40}$ Desdentado Bonete, A. La reforma del despido en el Real Decreto-ley 10/2010. En VVAA. La reforma laboral 2010. Aspectos Prácticos (GARCÍA-PERrote EsCARTín, I. y MERCADER Uguina, J.R., Dirs.). Valladolid: Lex Nova, 2010, pp.74 y ss.

${ }^{41}$ Circunstancia que se reconoce expresamente en el apartado II del Preámbulo de la Ley $35 / 2010$, al señalar que el motivo de la nueva redacción de las causas extintivas por despido colectivo u objetivo obedece a que «la experiencia obtenida en los últimos años ha puesto de manifiesto... algunas deficiencias en el funcionamiento de las vías de extinción previstas en los artículos 51 y 52.c) del TRLET, al desplazar muchas extinciones de contratos indefinidos realmente basadas en motivaciones económicas o productivas hacia la vía del despido disciplinario improcedente».
} 
viabilidad o a su capacidad de mantener el volumen de empleo. A estos efectos, la empresa tendrá que acreditar los resultados alegados y justificar que de los mismos se deduce la razonabilidad de la decisión extintiva para preservar o favorecer su posición competitiva en el mercado».

En realidad, en esta causa, como en el resto de las tipificadas, debiera sopesarse siempre el principio de conservación del negocio jurídico, subordinado al principio de conservación de la empresa, como «ente vivo» que debe adaptarse las circunstancias impuestas por el mercado. Sabiendo que el límite, por arriba, lo marca el estado de insolvencia «inminente», que es definido por la Ley 22/2003, de 9 de julio, Concursal, como la situación en la que se encuentra el deudor que prevea que no va a poder cumplir regular y puntualmente sus obligaciones (artículo 2.3), la difícil solución pasa por determinar hasta que punto el sacrificio de determinados puestos de trabajo resulta proporcional a la verdadera situación de la empresa, puesto que no se trata, simplemente, de «dejar de ganar». En definitiva, mientras que no se ponga en peligro la conservación de la empresa, su continuidad sin deudas que puedan preveer una insolvencia «inminente», las causas alegadas para el despido no deberían prosperar.

\subsection{Medidas para el reforzamiento de los instrumentos de flexibilidad inter- na}

16. A tal fin, la reforma se ha centrado en tres cuestiones.

\subsubsection{TRASLADOS COLECTIVOS Y MODIFICACIONES SUSTANCIALES DE LAS CON- DICIONES DE TRABAJO}

17. Con las medidas adoptadas en este ámbito (artículos 40 y 41 del TRLET), el legislador persigue «dotar al procedimiento de mayor agilidad y eficacia. Para ello:

(a) Se regula el carácter improrrogable del plazo previsto para los períodos de consulta, que no podrá ser superior a quince días.

(b) Se prevé una solución legal para los supuestos en que no existan representantes de los trabajadores en la empresa con quienes negociar: los trabajadores podrán optar por atribuir su representación para la negociación del acuerdo, a su elección, a una comisión de un máximo de tres miembros integrada por trabajadores de la propia empresa y elegida por éstos democráticamente o a una comisión de igual número de componentes designados, según su representatividad, por los sindicatos más representativos y representativos del 
sector al que pertenezca la empresa y que estuvieran legitimados para formar parte de la comisión negociadora del convenio colectivo de aplicación a la misma. En todos los casos, la designación deberá realizarse en un plazo de cinco días a contar desde el inicio del periodo de consultas, sin que la falta de designación pueda suponer la paralización del mismo. Los acuerdos de la comisión requerirán el voto favorable de la mayoría de sus miembros. En el supuesto de que la negociación se realice con la comisión cuyos miembros sean designados por los sindicatos, el empresario podrá atribuir su representación a las organizaciones empresariales en las que estuviera integrado, pudiendo ser las mismas más representativas a nivel autonómico, y con independencia de que la organización en la que esté integrado tenga carácter intersectorial o sectorial.

(c) Se potencia la utilización de medios extrajudiciales de solución de discrepancias: El empresario y la representación de los trabajadores podrán acordar en cualquier momento la sustitución del periodo de consultas por el procedimiento de mediación o arbitraje que sea de aplicación en el ámbito de la empresa, que deberá desarrollarse dentro del plazo máximo señalado para dicho periodo.

\subsubsection{Cláusulas de INAPLICACIÓN SALARIAL}

18. A través de las mismas, y modificando el artículo 82 del TRLET, relativo al concepto y eficacia de los convenios estatutarios, el legislador pretende aligerar el procedimiento existente.

Así, el nuevo procedimiento para posibilitar los descuelgues salariales presenta las siguientes características:

Por acuerdo entre la empresa y los representantes de los trabajadores legitimados para negociar un convenio colectivo estatutario de empresa o ámbito inferior, se podrá proceder, previo desarrollo de un periodo de consultas en los términos del artículo 41.4, anteriormente descrito, a inaplicar el régimen salarial previsto en los convenios colectivos de ámbito superior a la empresa, cuando la situación y perspectivas económicas de ésta pudieran verse dañadas como consecuencia de tal aplicación, afectando a las posibilidades de mantenimiento del empleo en la misma.

En los supuestos de ausencia de representación legal de los trabajadores en la empresa, éstos podrán atribuir su representación a una comisión designada conforme a lo dispuesto también en el artículo 41.4.

Cuando el periodo de consultas finalice con acuerdo se presumirá que concurren las causas justificativas para el descuelgue salarial, y sólo podrá ser impugnado ante la jurisdicción competente por la 
existencia de fraude, dolo, coacción o abuso de derecho en su conclusión. El acuerdo deberá ser notificado a la Comisión paritaria del convenio colectivo.

El acuerdo de inaplicación deberá determinar con exactitud la retribución a percibir por los trabajadores de dicha empresa, estableciendo, en su caso y en atención a la desaparición de las causas que lo determinaron, una programación de la progresiva convergencia hacia la recuperación de las condiciones salariales establecidas en el convenio colectivo de ámbito superior a la empresa que le sea de aplicación, sin que en ningún caso dicha inaplicación pueda superar el período de vigencia del convenio ni, como máximo los tres años de duración. El acuerdo de inaplicación y la programación de la recuperación de las condiciones salariales no podrán suponer el incumplimiento de las obligaciones establecidas en convenio relativas a la eliminación de las discriminaciones retributivas por razones de género.

Mediante los acuerdos interprofesionales de ámbito estatal o autonómico, previstos en el artículo 83 del TRLET, se deberán establecer los procedimientos de aplicación general y directa para solventar de manera efectiva las discrepancias en la negociación de los acuerdos en cuestión, incluido el compromiso previo de someter las discrepancias a un arbitraje vinculante, en cuyo caso el laudo arbitral tendrá la misma eficacia que los acuerdos en periodo de consultas y sólo será recurrible conforme al procedimiento y en base a los motivos establecidos en el artículo 91 del TRLET.

\subsubsection{REDUCCIÓN DEL TIEMPO DE TRABAJO}

19. El legislador hace especial hincapié en esta medida, al referirse «muy señaladamente» a la suspensión de contratos y reducción de jornada por causas económicas, técnicas, organizativas y de producción. En su opinión, esta medida «facilita el ajuste de la empresa a las necesidades cambiantes del mercado y, al mismo tiempo, proporciona al trabajador un alto grado de seguridad, tanto en la conservación de su puesto de trabajo, como en el mantenimiento de su nivel de ingresos económicos por la protección dispensada por el Sistema de protección por desempleo...».

Sobre esta medida la doctrina ha señalado que el legislador ha querido copiar «a la española» el exitoso modelo alemán de reducción de jornada, conocido como el Kurzarbeit ${ }^{42}$. No obstante, debe advertirse que el éxito del

${ }^{42}$ En torno al KuRZARBEIT se han referido entre nosotros, entre otros, GonZÁLEZ OrTEGA, S. La fascinación de los modelos o el Kurzarbeit a la española. En Aspectos Prácticos (GARCíAPerrote Escartín, I. y Mercader Uguina, J.R., Dirs.). Valladolid: Lex Nova, 2010, pp.181198; así como Brecht-Heitzmann, H. Medidas jurídicas laborales y de Seguridad Social para la lucha contra la crisis económica en Alemania. En TS, 2010, núm. 230, pp. 15-16. 
sistema alemán no sólo pasa por preveer esta medida, sino que también por su implementación rigurosa, en la que la negociación entre empresarios y representantes de los trabajadores se lleva a cabo con total lealtad y responsabilidad, así como por su buena coordinación con el Sistema de Seguridad Social, que no sufre tanto las desviaciones hacia esta medida, porque desde hace años se está fomentando, igualmente, el nivel complementario o libre de Seguridad Social. Con ello, quiere advertirse de los problemas que pueden plantearse desde el punto de vista de la financiación del Sistema de Seguridad Social.

Seguramente, se relaciona con tales problemas el hecho de que la reforma guarde silencio en torno aspectos como la jubilación parcial en cuanto medida de reparto de empleo ${ }^{43}$ o la conveniente nueva regulación del contrato fijo-discontinuo, eliminando las disfuncionalidades creadas por el fijoperiódico del artículo 12.3 del TRLET, que difícilmente encaja dentro del contrato a tiempo parcial ${ }^{44}$. Y junto a la reducción del tiempo de trabajo, tampoco puede pasar desapercibida la matización introducida en cuanto a las materias consideradas como objeto de las modificaciones sustanciales de las condiciones de trabajo, al referirse, ahora, junto al horario a la «distribución del tiempo de trabajo». En ese sentido, también se ha dejado pasar una nueva oportunidad para reestructurar el hace tiempo trasnochado artículo 13 del TRLET, relativo al trabajo a domicilio, con la finalidad de regular adecuadamente, entre otros aspectos, el teletrabajo como forma de organizar la prestación de servicios ${ }^{45}$.

20. Centrándonos en las medidas adoptadas en España, debe diferenciarse la regulación de la suspensión del contrato de trabajo de la regulación relativa a la reducción de la jornada, aunque ambas se contengan en el artículo 47 del TRLET, y se deban a causas económicas, técnicas, organizativas o de producción, o derivadas de fuerza mayor. Por consiguiente:

(a) Las especialidades de la suspensión del contrato radican en que:

\footnotetext{
${ }^{43} \mathrm{Al}$ respecto véase VICEDO CAÑADA, L. La jubilación parcial como medida de reparto de empleo en épocas de crisis. En Estudios Financieros. Revista de Trabajo y Seguridad Social: Comentarios, casos prácticos: recursos humanos, 2009, núm. 312, pp. 145-156.

${ }^{44}$ En el mismo sentido, véase MARTínez ABASCAL, V.A. Los trabajadores fijos periódicos y fijos discontinuos. En VVAA. Crisis, reforma y futuro del Derecho del Trabajo. Estudios ofrecidos en memoria del Profesor Ignacio Albiol Montesinos (CAMPS RuIZ, L.M., Ramírez Martínez, J.M. y Sala Franco, T., Coord.s). Valencia: Tirant lo Blanch, 2010, pp. 149-168.

${ }^{45}$ Véase sobre los aspectos laborales del teletrabajo ARRIETA IDIAKEZ, F.J. Lan-zuzenbidea eta gune ilun gisa kalifikatutako lan-harreman juridikoak (II): Telelanaren inguruko zertzelada batzuk. En Jado. Boletín de la Academia Vasca de Derecho, 2009, núm. 17, pp. 201-222.
} 
-El procedimiento será aplicable cualquiera que sea el número de trabajadores de la empresa y del número de afectados por la suspensión.

-El plazo a que se refiere el artículo 51.4, relativo a la duración del período de consultas, se reducirá a la mitad y la documentación será la estrictamente necesaria en los términos que reglamentariamente se determinen.

- La autorización de esta medida procederá cuando de la documentación obrante en el expediente se desprenda razonablemente que tal medida temporal es necesaria para la superación de una situación de carácter coyuntural de la actividad de la empresa.

—La autorización de la medida no generará derecho a indemnización alguna.

(b) La jornada de trabajo podrá reducirse: con arreglo al procedimiento recién descrito para la suspensión, si bien deberá entenderse por reducción de jornada la disminución temporal de entre un 10 y un 70 por ciento de la jornada de trabajo computada sobre la base de una jornada diaria, semanal, mensual o anual. Además, durante el período de reducción de jornada no podrán realizarse horas extraordinarias salvo fuerza mayor.

Del mismo modo, y sin ninguna otra especificación, cabe subrayar que el legislador establece que durante las suspensiones de contratos o las reducciones de jornada se promoverá el desarrollo de acciones formativas vinculadas a la actividad profesional de los trabajadores afectados cuyo objeto sea aumentar su polivalencia o incrementar su empleabilidad.

Por último, la posibilidad de reducir la jornada cuenta con los beneficios derivados de la protección por desempleo [artículos 203, 208 y 210 del Real Decreto legislativo 1/1994, de 20 de junio, por el que se aprueba el Texto Refundido de la Ley General de la Seguridad Social (TRLGSS) ${ }^{46}$ ] y de las medidas de apoyo a la reducción de jornada contenidas en la Ley 27/2009, de 30 de diciembre, de medidas urgentes para el mantenimiento y fomento del empleo y la protección de las personas desempleadas (artículo 1 y 3$)^{47}$.

\subsection{Medidas para el aumento de las oportunidades de las personas desem- pleadas}

21. La reforma ha focalizado el alcance de estas medidas en tres ámbitos.

${ }^{46}$ BOE de 29 de junio de 1994, núm. 154.

${ }^{47}$ BOE de 31 de diciembre de 2009, núm. 315. 


\subsubsection{BONIFICACIONES A LA CONTRATACIÓN INDEFINIDA}

22. La Ley 35/2010, ha introducido importantes cambios en la política de bonificaciones a la contratación indefinida, modificando el Programa de Fomento de Empleo establecido por la Ley 43/2006, de 29 de diciembre, para la mejora del crecimiento y del empleo ${ }^{48}$. Conforme a la síntesis realizada por OrTEga Prieto y ORTEGa FigueIRAL, las novedades más importantes al respecto son las siguientes ${ }^{49}$ :

(a) Se suprimen las bonificaciones universales para jóvenes, mujeres y parados de larga duración y se concentran en dos colectivos: Jóvenes desempleados entre 16 y 30 años, ambos inclusive, con especiales problemas de empleabilidad, y mayores de 45 años inscritos en la Oficina de Empleo al menos doce meses dentro de los dieciocho inmediatamente anteriores a la contratación.

(b) Se mantienen las actuales bonificaciones para la conversión de contratos formativos y de relevo en indefinidos, manteniendo el mismo importe, pero mejorando la cuantía cuando la contratación lo sea de trabajadoras.

(c) Todas aquellas bonificaciones en las cuotas empresariales de la Seguridad Social que se vinieran disfrutando por los contratos celebrados con anterioridad al 18 de junio de 2010, se regirán por la normativa vigente en el momento de su celebración o, en su caso, en el momento de iniciarse el disfrute de la bonificación.

(d) Como novedad muy relevante, que restringe o endurece el acceso a las bonificaciones debe destacarse que las nuevas contrataciones o transformaciones, a excepción del contrato de relevo, deben suponer un incremento de nivel de empleo fijo de la empresa y, adicionalmente, deben mantenerlo durante el período de duración de la bonificación.

(e) Los trabajadores de contratación indefinida inicial o de transformación de su relación temporal en indefinida serán objetivo prioritario en los planes de formación para personas ocupadas dentro de los programas de formación profesional para el empleo, así como de cualquier otra medida de política activa de empleo, al objeto de incrementar su cualificación profesional.

(f) Por último, debe destacarse que, al igual que sucede con la formalización de relaciones indefinidas y la transformación de aque-

${ }^{48}$ BOE de 30 de diciembre de 2006, núm. 312.

49 Ortega Prieto, E. y Ortega Figueiral, E. La reforma laboral 2010. Comentarios prácticos de la Ley 35/2010, de 17 de septiembre, de medidas urgentes para la reforma del mercado de trabajo. Madrid: La Ley, 2010, pp. 101-107. 
llas en temporales, la Ley 35/2010, a los efectos de potenciar la suscripción de contratos para la formación, establece toda una serie de bonificaciones novedosas.

\subsubsection{CONTRATOS FORMATIVOS}

23. Los aspectos novedosos sobre los contratos formativos inciden en una regulación más generosa para sus beneficiarios. Así, respecto al contrato de prácticas, las novedades se concentran en los siguientes aspectos: la extensión de títulos habilitantes para su celebración, la ampliación de los años tras la obtención del correspondiente título habilitante durante los que se posibilita la celebración de este contrato, la mejora prestacional del Sistema de Seguridad Social y la regulación de ciertas salvaguardas para evitar el fraude en la utilización de este contrato. Por su parte, los cambios son más notorios en la regulación del contrato para la formación, debido a sus implicaciones con las políticas activas de empleo y con el subsistema de formación profesional. Igualmente, se mejora la protección otorgada por el Sistema de Seguridad Social.

24. Ahora bien, a pesar de las mejoras introducidas, nuevamente se ha perdido la ocasión para vincular definitivamente el mundo universitario y de la formación profesional con el mercado de trabajo. Como complemento a la postergación de la edad de jubilación, debe buscarse una solución a la tardía inserción y con todas las garantías al mercado de trabajo. Para ello, superando la actual situación de «zona gris» en la que se encuentran sumidas las distintas relaciones de beca, resulta imprescindible regular un nuevo contrato de beca, al margen, claro está, del Derecho del Trabajo, que posibilite compaginar los estudios con la realización de actividades prácticas/productivas en actividades relacionadas con dichos estudios, con unos mínimos derechos retributivos y prestacionales, vía actualización del obsoleto seguro escolar.

\subsubsection{MECANISMOS DE INTERMEDIACIÓN LABORAL}

25. Parece ser que la desastrosa experiencia española en esta materia va a continuar por parecidos derroteros. Hasta la fecha, la ineficacia ha sido el rasgo más característico del sistema de intermediación. Para contrastar tal afirmación basta con tomar en consideración el análisis realizado por PÉREZ De Los Cobos ORIHUEL ${ }^{50}$.

Según este autor, el papel desempeñado por los servicios públicos de empleo es mínimo, siendo su tasa de registro, a marzo de 2010, inferior al $8 \%$ del total de colocaciones con demanda activa de empleo, y en torno al

${ }^{50}$ Pérez De Los Cobos Orinuel, F. La reforma de la intermediación laboral en España. En $A L, 2010$, núm. 5. Versión electrónica: www.laleylaboral.com., pp. 4 y 5. 
$2 \%$ si se toma en cuenta el total de las colocaciones ${ }^{51}$; por su parte, las agencias privadas de colocación sin ánimo de lucro tampoco han penetrado verdaderamente en el mercado de trabajo, ya que a falta de datos sobre las colocaciones que intermedian, es esclarecedor el hecho de que el número de agencias existente es sólo de 72 y que esta cifra ha permanecido inamovible desde 2001. Finalmente, se constata, que son las empresas de trabajo temporal quienes más colocaciones realizan en España, a pesar de que éstas no pueden actuar en algunos sectores importantes como la construcción y las Administraciones.

Así las cosas, la reforma laboral ha supuesto la creación de nuevas agencias privadas de colocación, ahora también con ánimo de lucro, y la trasposición al ordenamiento jurídico español de la Directiva 2008/104/CE, de 19 de noviembre de 2008, relativa al trabajo a través de empresas de trabajo temporal ${ }^{52}$.

26. Respecto a las agencias privadas de colocación, la reforma ha introducido la posibilidad de que estas sean con ánimo de lucro, procediéndose a la modificación de la Ley 56/2003, de 16 de diciembre, de Empleo (artículos 20, 21bis, 22, 22bis, 27, 28 y Disposición Adicional sexta) ${ }^{53}$, del TRLET (artículo 16), del TRLGSS (artículo 231) y del TRLISOS (artículos 16, 17, 24 y 25$)$.

Al mismo tiempo, la Ley 56/2003 ha dispuesto la posibilidad de que las agencias de colocación autorizadas podrán ser consideradas entidades colaboradoras de los servicios públicos de empleo mediante la suscripción de un convenio de colaboración con los mismos (artículo 21.bis.5), y ha calificado a las empresas de recolocación como agencias de colocación especializadas en la actividad de intermediación laboral destinada a la recolocación de los trabajadores que resultan excedentes en procesos de reestructuración empresarial, siempre que dicha actividad se establezca o acuerde con los trabajadores o sus representantes en los correspondientes planes sociales o programas de recolocación (artículo 21.bis.1, en relación con el artículo 20.2).

Sin embargo, las agencias privadas de colocación con ánimo de lucro no serán una realidad hasta que reglamentariamente se concrete y desarrolle su ámbito de actuación, funciones, requisitos administrativos e instrumentos de

${ }^{51}$ La poca eficacia de los Servicios Públicos de Empleo se debe, igualmente, a las disfuncionalidades que originó en su día la descentralización del antiguo INEM por la falta de coordinación entre los servicios públicos de las distintas comunidades autónomas, que contaron incluso con distintos servicios informáticos. Sobre esta cuestión, véase VALDÉs DALRE, F. Cooperación y coordinación entre los Servicios Públicos de Empleo. En RL, 2009, núm. 4. Versión electrónica: www.laleylaboral.com., p. 3.

${ }^{52}$ Vid. extensamente FeRnÁndez Collados, M.B. Servicios públicos de empleo y agencias de colocación. En VVAA. Guía práctica de la reforma laboral de 2010 (CAVAS MARTíNEZ, F. y Luján AlCARAZ, J., Coords.). Murcia: Laborum, 2010, pp. 223-265.

${ }^{53}$ BOE de 17 de diciembre de 2003, núm. 301. 
control. Desarrollo reglamentario que, en principio, debería producirse por el Gobierno antes del 31 de diciembre de 2010, previa negociación con los interlocutores sociales y con las comunidades autónomas (Disposición Final tercera de la Ley 35/2010).

27. En relación con las empresas de trabajo temporal, como consecuencia de la trasposición del reglamento mencionado, la reforma, además de profundizar en el principio de igualdad de trato en las condiciones laborales entre los trabajadores cedidos y los trabajadores de las empresas usuarias (artículos 11, 16 y 17 de la Ley 14/1994, de 1 de junio, por la que se regulan las empresas de trabajo temporal ${ }^{54}$ ), se ha centrado básicamente en la supresión de límites y prohibiciones de actuación en los denominados sectores excluidos, a saber, los sectores de riesgo, y dentro de los mismos, con especial importancia, la construcción, y el sector público.

Como excepción a la norma general, entre los denominados sectores de riesgo no podrán ser objeto de la actividad de las empresas de trabajo temporal: los trabajos que impliquen la exposición a radiaciones ionizantes; los trabajos que impliquen la exposición a agentes cancerígenos, mutagénicos o tóxicos para la reproducción; y los trabajos que impliquen la exposición a agentes biológicos (Disposición Adicional segunda de la Ley 14/1994).

Lo que sucede es que las prohibiciones y limitaciones existentes para que las empresas de trabajo temporal actúen en los campos mencionados persistirán hasta el 1 de abril de 2011, por lo que una vez más queda postergada la aplicación de las medidas introducidas por la reforma (Disposición Adicional cuarta de la Ley 14/1994).

Pero, sin lugar a dudas, el mayor error en que ha incurrido la reforma consiste en mantener la rígida separación entre empresas de trabajo temporal y agencias de colocación, en la medida en que el objeto de las primeras (la contratación de trabajadores para cederlos a otras empresas) resulta exclusivo para las mismas y excluyente para los demás agentes que intervienen en la intermediación laboral. Como ha advertido parte de la doctrina, hubiese sido mucho más coherente no crear las agencias de colocación privadas con ánimo de lucro y centralizar todas sus funciones en las empresas de trabajo temporal, dada su experiencia y, tal y como se ha observado, teniendo en cuenta sus datos mucho más positivos respecto al nivel de colocación, en comparación con los servicios públicos de empleo y las agencias de colocación privadas sin ánimo de lucro que venían funcionando con anterioridad de la reforma ${ }^{55}$.

${ }^{54}$ BOE de 2 de junio de 1994, núm. 131.

${ }^{55}$ Dorrego De Carlos, A. La reforma de la intermediación laboral en la Ley 35/2010: perspectiva desde el sector de las ETT. En Diario La Ley, 2010, núm. 7488, Sección Tribuna. Versión electrónica: www.laleylaboral.com., pp. 2 y 6. En el mismo sentido, PÉREZ DE Los Cobos Orinuel, F. La reforma laboral: un nuevo marco legal para las empresas de trabajo temporal. En $A L, 2010$, núm. 16. Versión electrónica: www.laleylaboral.com., p. 7. 